\title{
Silêncio e ausência de cor em manchetes jornalísticas de caráter racial: práticas autorais de escrita para outras (res)significações de sentidos
}

\author{
Angelo Roberto Gonçalves Ribeiro* \\ Janaína Zaidan Bicalho Fonseca**
}

\begin{abstract}
Resumo
Este artigo $^{1}$ objetiva apresentar um exercício de escrita mediada por uma perspectiva dialógica da linguagem. Para isso, valemo-nos de um trabalho pautado na paráfrase e na reconstrução de sentidos, a partir da reescrita, empreendida por um acadêmico de Letras, de manchetes jornalísticas de caráter racial, fundadas desde uma visão preconceituosa e excludente. A ideia desenvolvida girou em torno da ressignificação de sentidos, tomando como direção escolhas e posicionamentos próprios do produtor do texto, num encaminhamento autoral de escrita. A perspectiva teórica baseouse nas categorias conceituais bakhtinianas, tanto no tocante à análise das manchetes, quanto no que diz respeito às análises metadiscursivas empreendidas pelo autor das reescritas.
\end{abstract}

Palavras-chave: Escrita. Autoria. Reconstrução de sentidos.

\footnotetext{
* Mestrando em Letras pela Universidade de São Paulo (USP). Graduado em Letras - Português e Espanhol pela Universidade Federal do Triângulo Mineiro (UFTM). ORCID: https://orcid.org/0000-0002-8485-4753.

** Doutora em Linguística e Língua Portuguesa pela Pontifícia Universidade Católica de Minas Gerais (PUC Minas). Professora adjunta da Universidade Federal do Triângulo Mineiro (UFTM). E-mail: janaina.fonseca@uftm.edu.br. ORCID: https://orcid.org/0000-0002-1210-4910

1 Esse artigo está inscrito no projeto de pesquisa intitulado Leitura e escrita no Brasil, Honduras, Angola e Chile: formação na universidade contemporânea e (re)produção de conhecimento, aprovado pelo CNPq por meio da Chamada Universal MCTIC/CNPQ N.o 28/2018, Processo: 4/27044/2018-9. Está, ainda, atrelado às pesquisas do projeto de pesquisa Metodologias para o ensino da escrita na universidade: discursos e saberes na produção do conhecimento, sem financiamento e apoiado pela Universidade Federal do Triângulo Mineiro (UFTM).
}

Cadernos CESPUC de Pesquisa. Série Ensaios. n.37, $2^{\circ}$ Sem./2020, p. 179-199. e-ISSN: 2358-3231 (OJS). Recebido em: 07/08/2020. Aceito em: 19/10/2020. 


\title{
Silence and Absence of Color in Journalistic Headlines of Racial Character: Authoral Wrinting Practices for Other (Res)Meanings of Meanings
}

\author{
Angelo Roberto Gonçalves Ribeiro \\ Janaína Zaidan Bicalho Fonseca
}

\begin{abstract}
This article aims to present a writing exercise mediated by a dialogical perspective of language. For this, we use a work based on the paraphrase and the reconstruction of meanings, based on the rewriting, undertaken by a Literature scholar, of journalistic headlines of a racial character, founded on a prejudiced and exclusive view. The developed idea revolved around the resignification of meanings, taking as choices the own choices and positions of the text producer, in an authorial direction of writing. The theoretical perspective was based on the Bakhtinian conceptual categories, both with regard to the analysis of the headlines, and with regard to the meta-discursive analyzes undertaken by the author of the rewrites.
\end{abstract}

Keywords: Writing. Authorship. Reconstruction of meanings. 


\section{Trajetórias e encaminhamentos}

Surgido em um contexto de retrocesso histórico, no qual se assiste a um explícito ataque às camadas populares do nosso país, este artigo nasceu como proposta de trabalho final da disciplina de Linguística Aplicada, a qual se comprometeu em entender a diferença estabelecida pela linguagem, no constante enfraquecimento de grupos sociais invisibilizados. Nossa intenção foi a de conduzir um trabalho que refletisse sobre como esses grupos são hierarquizados socialmente a partir dos usos feitos da linguagem - objeto de poder constantemente manobrado para o benefício de uma dada ordem discursiva.

Nesse sentido, defendemos a importância de questionar as lógicas sob as quais os enunciados costumam ser construídos nas diferentes esferas de circulação, propondo novas formas, mais conscientes e éticas, de construir os discursos. Apostamos, para isso, na ruptura e na reconstrução dos modos de dizer, estabelecendo uma polifonia controversa com manchetes jornalísticas de caráter racial. Pretendemos, com isso, colocar em análise como esses textos focalizam os negros como alvo da violência e da negligência social, na tentativa de problematizar a construção de sentidos resultantes do apagamento da adjetivação e da naturalização do preconceito em nossa sociedade. A adoção dessa abordagem enunciativa pela mídia certamente está atrelada ao nosso passado histórico de escravidão, cuja dívida moral ainda não foi saldada, prolongando-se discursivamente por meio de uma materialidade linguística que revela forte inclinação para a exclusão social dos negros. É nesse sentido que este artigo pretende caminhar: observando, nas práticas discursivas, como o negro é construído, a fim de buscar compreender o pensamento político e ideológico sustentado na superfície textual.

Para além disso, este estudo também buscou, à luz da reconstrução de sentidos, ressignificar o grupo social vítima de marginalização, lançando mão da reescrita das manchetes, no intuito de tensionar, dialogicamente, a perpetuação dos modos de dizer sobre o negro, cristalizados historicamente. Assim, é na pretensa regulação polifônica que se deseja demonstrar novas formas de referenciação ao negro no curso discursivo. 
Pensando nisso, compreendemos que a paráfrase dos textos que constituem nosso corpus de análise contribui na mobilização de sentidos outros que colocam em jogo uma consciência autoral construída por intermédio da linguagem, uma vez que colocamos em funcionamento signos linguísticos orquestrados sob matriz ideológica que se diferencia da matriz fundadora dos discursos primeiros. Assim, não criamos apenas inteligibilidades sobre esses discursos, mas construímos, na recriação polifônica, novas formas de entendê-los e de torná-los insubmissos à cultura dominante entronizada no nosso país.

Dessa forma, a Linguística Aplicada discutida no bojo deste artigo relaciona-se com as alternativas de co-criação discursiva, pautadas na inversão ideológica e, sobretudo, no exercício de constituição autoral compreendido como ato responsivo do dizer, ou seja, com a movimentação de um lugar valorativo do dizer, que coloca o sujeito que escreve na regulação consciente do que é dito. Trata-se, pois, de uma posição estético-formal, na qual se encena o dizer do outro, a partir de performances genuínas de escrita.

Sob essa direção, o protagonismo na construção de posturas discursivas é posto em foco, permitindo a estudantes de graduação - como recentemente já o foi o primeiro autor deste artigo - imergir em práticas de escrita assumidas desde a sua vontade autoral. Portanto, para nós, a Linguística Aplicada não está restrita ao contexto educacional como o de graduação, mas não negamos sua extrema importância nesse cenário, já que a formação do acadêmico de Letras está atrelada às descobertas das potencialidades do seu dizer e, consequentemente, a como esse mesmo dizer poderá ser ensinado em sala de aula, partindo de uma modificação na forma de se ensinar a escrever - não mais como produto de uma visão una, segura e acabada de texto, mas como fruto de posicionamentos que marcam o ser e o estar de um sujeito no mundo.

A fim de cumprirmos com os objetivos pautados até aqui, selecionamos um pequeno corpus de manchetes, do ano de 2019, publicadas em mídia digital, correspondentes a jornais de diferentes regiões do país. Em todas elas, observamos um direcionamento preconceituoso e excludente por parte das instituições de segurança pública acerca do assassinato de cidadãos brasileiros negros, em uma abordagem que relativiza a violência e apaga a vítima. $\mathrm{O}$ apagamento, nesse caso, contribui para a manutenção de um juízo 
coletivo, que priva o leitor de uma capacidade emancipatória e autônoma de atribuição de sentido, provocando uma sensação de normalidade e de relativização da violência. Tais sensações são potencializadas pela ilusão da audição e da visão, na medida em que o silêncio e a falta de cor afetam as percepções sensórias do leitor. São essas impressões, porém, que desejamos resgatar no exercício de escrita empreendido neste artigo.

\section{Ferramentas conceituais}

Neste artigo, escolhemos trabalhar com um quadro teórico que mobilizasse os interesses da Linguística Aplicada, "como área centrada na resolução de problemas da prática de uso da linguagem" (MOITA-LOPES, 2006, p. 18). Somamos a isso a preocupação da área em dar voz aos que estão à margem da sociedade, problematizando e politizando os discursos que os afetam. A Linguística Aplicada que nos move, portanto, é aquela que destina um lugar à construção da vida social por intermédio da linguagem.

Sob esse foco, interessa-nos, especialmente, as particularidades dos discursos e as possibilidades de modificá-los, conforme se dá a busca por novas bases de sentido. Isso porque, numa chave ética do dizer, nem todos os significados nos parecem válidos e, portanto, nem todos devem fazer parte da nossa constituição cidadã. Dito isso, acreditamos no caráter inacabado e infinito do diálogo, considerando o mosaico polifônico a que os dizeres estão submetidos. Nessa medida, as ferramentas conceituais, como polifonia, dialogismo, ideologia, autoria, ato responsivo, posição estéticoformal, lugar valorativo do dizer, nos impelem a uma análise dialógica ou bakhtiniana para o tratamento discursivo.

A primeira lição que buscamos trazer para esse trabalho diz respeito à compreensão ativa que aciona enunciados únicos no tempo e espaço da enunciação, isto é, os elementos linguísticos individuais que demarcam uma situação enunciativa não são reiteráveis, uma vez que há um contexto histórico concreto que os origina, assim como um posicionamento ideológico que os motiva. No nosso caso, a geração de sentido com a qual nos comprometemos dialoga com os efeitos dos enunciados jornalísticos, mas com o intuito de negá-los e confrontá-los. No dizer de Bakhtin, "aquele 
que apreende a enunciação de outrem não é um ser mudo, privado da palavra, mas ao contrário um ser cheio de palavras interiores" (BAKHTIN, 2009 [1929], p. 153). Assim, a mobilização do signo ideológico e plurivalente possibilitou assumir um lugar de enfrentamento no texto, nutrindo o sujeito da escrita ${ }^{2}$ de palavras próprias que remarcaram a superfície textual. Buscamos, pois, dar sentido à palavra, de forma que o produtor do texto se visse refletido nessa nova escrita, estabelecendo outro tipo de relação com o discurso alheio, qual seja, o de não submissão.

A partir dessa concepção de escrita - dialógica e singular, a autoria foi se apresentando nas novas manchetes, refletindo as individualidades do ser escrevente e as imprescindíveis tensões decorrentes desse processo. Nas palavras de Sobral, ser autor é "assumir, de modo permanentemente negociado, posições que implicam diferentes modalidades de organização dos textos" (SOBRAL, 2012, p. 131), ou seja, ainda que os enunciados jornalísticos tenham sido retomados na ação de reescrita, os modos de dizer eram constantemente balizados, já que não interessava à atividade didática destruir por completo o dizer primeiro, mas redefini-lo conforme os limites sintático-enunciativos postos em movimento. $\mathrm{O}$ que significa dizer que "a posição do autor com respeito ao conteúdo de seu enunciado é ativa, mas não o coloca acima de todas as influências que incidem sobre seu agir em seu ambiente sócio-histórico" (SOBRAL, 2012, p. 127). Nessa direção, a atividade de escrita proposta teve como objetivo a expressão da individualidade do autor, de forma que a linguagem não se apresentasse despersonalizada (BAKHTIN, 2013 [1942-1945], p. 41).

Dessa maneira, a concepção de escrita trazida por este artigo está associada às potencialidades dialógicas da palavra - construída na tensão entre vozes diversas, cada qual com uma posição própria. O papel do sujeito é harmonizar essas vozes e, a partir delas, assumir o seu lugar no texto. E isso só se faz na medida em que se estabelece um exercício responsivo com a palavra, ou seja, em que se assume o que é falado.

É exatamente esse exercício, realizado por um aluno de graduação, inserido em um contexto histórico e social específico, que queremos demonstrar no decorrer deste artigo. Para isso, lançamos mão, após as

\footnotetext{
2 Sujeito da escrita, produtor do texto ou ser escrevente são expressões que remetem diretamente ao primeiro autor deste artigo, que, no ano de 2019, era graduando do Curso de Letras da Universidade Federal do Triângulo Mineiro (UFTM) e cursista da disciplina de Linguística Aplicada. O exercício de escolha do corpus, análise e reescrita é de sua responsabilidade; enquanto coube à segunda autora, a partir de seu lugar como professora, propor e orientar a atividade de escrita, bem como redefinir, para este artigo, os encaminhamentos teórico-metodológicos.
} 
reescritas, de um movimento metaenunciativo, em que o locutor encaminha as próprias reflexões acerca do texto que escreve, operando sobre os enunciados que produz. Embora partindo de modos de dizer já inscritos no corpo social, o dizer, uma vez reelaborado por um segundo produtor de texto, segue encaminhamentos outros que, na experiência didática em pauta, são elucidados, a fim de que o exercício autoral se faça visível.

É significativo salientar a importância da formação desse jovem estudante e a sua construção de repertório. Inicialmente, mobilizando conhecimentos aprendidos em uma universidade pública; posteriormente, pesquisando contributos outros em diferentes esferas sociais, para fundamentar a sua análise e a sua produção escrita.

Além disso, é possível observar a natureza da problematização e seus efeitos. O pensar e produzir uma reflexão gera repercussões significativas em cadeia, ou seja, um estudante formado em uma instituição pública, gratuita e de qualidade pode contribuir com a sociedade a fim de possibilitar ainda mais reflexão acerca da linguagem, alcançando novos indivíduos.

Tal problematização, em uma sociedade tão desigual como a brasileira, em diversos aspectos produz efeitos de autorreconhecimento, revela ainda as discriminações de indivíduos perante os recortes de classe, de raça e de gênero, além de provocar inquietações e inconformidades em relação ao status quo.

Para essas análises, o acadêmico se viu diante de um dilema, pois ainda desconhecia a sua legitimidade em propor uma discussão acerca desse tema. Por um lado, por não se reconhecer apto a apresentar e fundamentar a discussão academicamente e, por outro, por não se sentir seguro em relação ao seu local de fala, reconhecido como homem branco.

Esse impasse e presente cautela em emprenhar tal empreendimento é sustentado pelo pouco que o acadêmico conhece sobre os Estudos Culturais e suas problemáticas. É sabido que, dentro das pesquisas dos Estudos Culturais, há a contestação dos limites socialmente construídos (por exemplo, de classe, género, raça, etc.) nas mais diversas realidades humanas. 'A 'naturalização' dessas categorias tem sido precisamente objecto de grande contestação a partir dos Estudos Culturais” (BAPTISTA, 2009, p. 452).

A partir desses conhecimentos adquiridos para além dos muros da instituição educacional, o acadêmico se reconheceu como um possível 
agente social que poderia contribuir para uma reflexão, o que legitima a eficácia da interdisciplinaridade e a mobilização de conhecimentos em diversas áreas do conhecimento.

A respeito do local de fala, sustentou-se a partir da contribuição da filósofa Djamila Ribeiro, mulher, negra, escritora e acadêmica brasileira, que confere a todo indivíduo a sua autoridade em se posicionar desde seu lugar. Ainda, conforme a autora, é comum "achar que só o negro pode falar de racismo, se estamos em relações raciais e relações de gênero é importante que as outras pessoas debatam sobre esse tema" (RIBEIRO, 2019, on-line). Desse modo, "todo mundo tem lugar de fala, .... Porque está localizado socialmente, mas é como falar a partir do seu lugar sobre outras questões" (RIBEIRO, 2019, on-line). Portanto, "a pessoa branca deve discutir o racismo até porque faz parte do grupo que historicamente se beneficia dele, mas ela vai discutir a partir de um outro lugar" (RIBEIRO, 2019, on-line).

A partir dessas contribuições, veio a segurança em se posicionar e pensar, a partir das manchetes jornalísticas, a situação de apagamento do negro que estampa o chamariz das notícias. O interessante é refletir como o acadêmico, sendo uma pessoa "branca, pode pensar a situação racial no Brasil que passa por desnaturalizar lugares, por exemplo, que passa a começar a se incomodar a se questionar" (RIBEIRO, 2019, on-line).

Além das contribuições teóricas sinalizadas até o momento, o acadêmico encontrou em uma linguista brasileira, popularizada pelas redes sociais, uma discussão profícua e direcionada às manchetes jornalísticas. Jana Viscardi produz conteúdo sobre linguagem em seu canal no Youtube. A linguista, além de questionar os discursos que ecoam na sociedade, faz divulgação científica. Em suas palavras, ela é:

Uma linguista que procura olhar para a maneira como as manchetes são produzidas, como textos são escritos, para tentar justamente mostrar a importância da linguagem. Nesse sentido o meu trabalho é um trabalho de divulgação científica que pretende justamente trazer cada vez mais para perto das pessoas, ... o olhar de como a linguagem é importante para aquilo que nós experimentamos da realidade, para aquilo que nós recortamos da realidade, e como contexto é importante também dentro disso (VISCARDI, 2020, on-line). 
Diante de todas essas contribuições, institucionais e nãoinstitucionais, prestigiadas e não prestigiadas, o acadêmico passou a pensar sobre a possibilidade de escrita, bem como sobre a reflexão da autoria concebida a partir da reconstrução de sentidos revelada neste artigo.

\section{Ditos e (re)ditos do corpus}

A amostragem para a construção deste trabalho diz respeito às manchetes publicadas em mídia digital, correspondentes a jornais de diferentes regiões do país. Em todas elas, observa-se uma abordagem preconceituosa e excludente por parte das instituições de segurança pública acerca do assassinato de cidadãos brasileiros negros, a partir do apagamento da vítima.

As três primeiras retomam uma fala do presidente da República, mediada por uma heterogeneidade marcada pelo discurso direto. Logo após, em um encaixe sintático, segue-se um enunciado representativo da voz dos jornais que o aludiram. Trata-se, conforme lição bakhtiniana, do discurso de outrem entrando "no discurso e na sua construção sintática, por assim dizer, 'em pessoa', como uma unidade integral da construção" (BAKHTIN, 2009 [1929], p. 150). É como se o jornal narrasse a voz do presidente, a partir de suas próprias escolhas linguísticas; sem deixar, no entanto, que haja "a diluição da palavra citada" [...] "de tal forma que a substância do discurso do outro permanece palpável” (BAKHTIN, 2009 [1929], p. 151). Nas escolhas realizadas pelas propostas parafrásicas, também foram tomados caminhos que retomam as vozes da exclusão e da ausência ética, porém, descontruídas em recursos linguísticos comprometidos com outra matriz de sentido.

Com a finalidade de demonstração analítica, colocamos em tela o primeiro texto, publicado por jornal brasiliense, em abril de 2019: 


\section{'O Exército não matou ninguém, não', diz Bolsonaro sobre músico fuzilado}

Presidente falou pela primeira vez desde que o caso ocorreu, em 7 de abril, e disse que o fato se tratou de um "incidente"

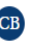

Correio Braziliense

Fonte: Correio Braziliense (2019)

Conforme podemos observar, a manchete do Correio Braziliense inicia-se com um enunciado proferido verbalmente pelo atual presidente da República, seguido de um verbo declarativo. Esse mecanismo é reconhecido por meio das aspas, graficamente marcadas, que denotam essa constatação. $\mathrm{O}$ texto usa esse recurso com o intuito de chamar atenção para o dito e explicitar claramente o posicionamento do emissor, buscando uma suposta posição de imparcialidade ao informar. Apesar disso, observa-se um embate polifônico, pois, quando se afirma que o músico foi fuzilado, nega-se ou desmerece-se a informação primeira de que o Exército não teria matado ninguém. Logo, a manchete é construída em um processo de tensão discursiva que, ao ativar o verbo "fuzilar", aciona uma rede semântica comum ao espaço militar. Se semanticamente chega-se a essa conclusão, sintaticamente a construção da sentença não obriga o uso de agente da passiva (fuzilado por alguém), sendo esta a estratégia argumentativa encontrada pelo jornal para manter a encenação de imparcialidade.

É importante contextualizar que o carro de uma família negra foi alvejado por 80 tiros durante uma operação do Exército que caçava um delinquente, e tinha como suspeita as características daquele carro. $\mathrm{O}$ motorista, negro, pai, músico, segurança, morreu. A manchete jornalística silencia-se, pois não é possível, ao lê-la, inferir que o crime teria motivação preconceituosa por parte do Exército, uma vez que o apagamento da adjetivação da cor da pele das vítimas resulta na impossibilidade de o leitor estabelecer uma conexão sobre a possível motivação do crime. 
Baseado em uma suposta imparcialidade dos fatos, o jornal apaga a possível motivação do crime, escolhendo adjetivar a vítima por sua profissão, a de músico, privando os leitores da atribuição de sentido de racismo, pois a questão da cor da pele da vítima e de sua família é importantíssima para a completa notificação dos fatos e posterior possibilidade de interpretação do leitor.

$\mathrm{Na}$ reconstrução de sentido, a proposta se baseou na evidenciação das marcas de exclusão social sofrida pelos negros, grupo marginalizado socialmente e objeto de análise desse trabalho. Porém, até aqui, é possível observar não marcas, mas o seu apagamento, é dizer, elas existem, mas em um nível interpretativo mais atento, menos visível, não expresso na superfície textual. É possível constatar que a manchete jornalística não é suficiente para expressar o tamanho da violência a respeito desse grupo atingido - uma minoria social que carece de atenção sobre seus direitos básicos. Ela não dá conta da problematização e tampouco causa algum efeito reflexivo na população, ao contrário, mantém um olhar passivo, encapuzado pelo falso sentido de imparcialidade jornalística, legitimando um posicionamento de naturalização diante das violências contra as minorias.

Proponho, por isso, a seguinte reescrita: "O Exército não matou ninguém, não", afirma presidente brasileiro negando óbvio fuzilamento de natureza racista. Resolvi trocar o verbo declarativo "diz" para "afirma" com o propósito de expressar segurança na retomada discursiva. Troquei "Bolsonaro" por "presidente brasileiro" em uma tentativa de enfatizar a escabrosa declaração feita por uma autoridade máxima do país. Utilizei também o verbo "negar" e o adjetivo "óbvio" resultante do sentido que o acontecido é um fato, aquilo que não pode ser mudado, nem alterado. Foi, ainda, adicionada a motivação do crime de "natureza racista" para explicitar e marcar os agentes da ação, assim como evidenciar a violência sofrida pela família.

$\mathrm{Na}$ continuidade das análises, a segunda manchete, divulgada por um jornal belo-horizontino, segue a mesma performance sintáticoenunciativa da primeira, no resguardo da voz do presidente: 


\section{'O Exército não matou ninguém não': Bolsonaro classifica fuzilamento com 80 tiros como 'incidente'}

De Redaçâo v 22 horas atrás

Fonte: BHAZ (2019)

A manchete do jornal belo-horizontino adota um posicionamento, que pode ser compreendido de maneira irônica ao juntar a negativa redundante "não matou ninguém não", com "fuzilamento com 80 tiros" e "incidente".

A construção desse enunciado evidencia um posicionamento contrário às declarações do presidente, afinal, é inconcebível um atentado dessa natureza não matar ninguém. $O$ título da reportagem responsabiliza o autor do enunciado por meio do verbo "classificar", ou seja, o presidente da República classifica o fuzilamento com 80 tiros como um "incidente". Desse modo, o enunciado atua como juízo de valor criticando Bolsonaro e enfatizando a sua intenção de repelir a responsabilidade do autor da ação: o Exército.

Percebemos que a manchete retoma o caso, por meio da alusão "fuzilamento com 80 tiros", mas não acrescenta nada a respeito dos envolvidos na ação, pois o que cabe aqui é o foco sobre o posicionamento do presidente em relação ao crime; e é irrelevante saber sobre as pessoas envolvidas, encarado como assunto já enterrado. Essa adoção enunciativa reflete também um posicionamento, já que, ao apagar tais informações, coopera para o silêncio dos inocentes, para o abrandamento de uma consciência social, para a impossibilidade de discussão.

Em vista disso, reescrevo: "O Exército não matou ninguém não": presidente nega fuzilamento com 80 tiros a carro de família negra e classifica ação como "incidente.' Propus a alteração do verbo "classificar" por "negar" e adicionei mais detalhes sobre as vítimas, assim motivando uma atribuição de sentido mais direcionada a respeito da classificação de "incidente" por parte do presidente. Também alterei "Bolsonaro" para "presidente" - função 
de fácil reconhecimento do emissor, uma autoridade, tentando trazer uma responsabilidade para o cargo.

Finalizando as manchetes que retomam o mesmo enunciado pronunciado pelo presidente da República, apresento o seguinte texto de um jornal salvadorense:

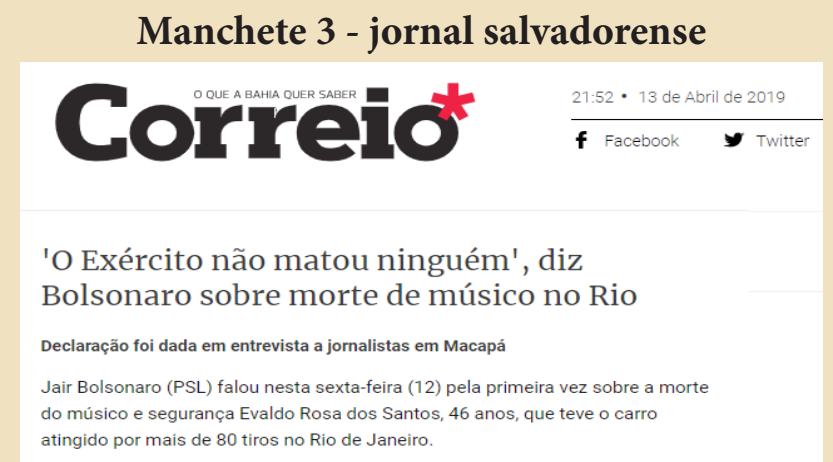

Fonte: Correio - O QUE A BAHIA QUER SABER (2019)

Até aqui podemos perceber uma constante adoção sobre a adjetivação e o foco enunciativo a respeito do crime cometido pelo Exército contra uma família negra dentro de um carro em movimento.

A manchete do jornal baiano retoma a notícia em discurso direto seguida de um verbo declarativo, relativizando o assassinato e adjetivando a vítima como músico. Na segunda linha dá mais detalhes, porém novamente adota um posicionamento que favorece um afastamento da motivação. Detalhes redundantes que nada contribuem para uma reflexão social. Adjetiva duas vezes a vítima, músico e segurança, com adjetivos de natureza profissional; esclarece sua idade e oculta os outros integrantes que também estavam no carro e, por fim, nada revela.

O que impressiona é a escolha de um jornal que tem em seu nome "o que a Bahia quer saber" (CORREIO, 2019, on-line), cujo estado conta com o maior número de pessoas que se declaram pretas, se posicionar dessa maneira (UOL, 2013, on-line). Desse modo, temos um triângulo isósceles, de dois lados iguais, representado por um presidente que nega fatos e um jornal "imparcial" que não menciona a autoria de um crime, afetando uma minoria marginalizada e apagada. 
Com objetivo de evidenciar o lado silenciado, propus a seguinte reescrita: Exército mata músico negro no Rio e presidente da República diz: "O Exército não matou ninguém". Diante da reescrita da manchete, tentei marcar duas opiniões, a do jornal e a do presidente. Ainda indico a condição do homem baleado adicionando o adjetivo negro após músico, possibilitando uma problematização social sobre a motivação do crime. Alterei também "Bolsonaro" por "presidente da República" a fim de instalar um sentido de inadequação do enunciado proferido com as responsabilidades do cargo.

Terminadas as manchetes relacionadas à retomada explícita da fala do presidente, segue-se o quarto corpus selecionado para análise, no qual ainda se observa a predileção do discurso direto; agora, porém, correspondente à voz do general Heleno:

\section{Manchete 4 - jornal paulistano

$$
\text { SEGURANÇA PÚBLICA }
$$

\section{Comandante de ação com 80 tiros no RJ "deu uma bobeada", diz general Heleno}

Fonte: Universo Online, UOL, Grupo Folha (2019)

$\mathrm{O}$ infeliz enunciado, em discurso direto evidenciado por meio das aspas, atinge uma barbárie institucionalizada. A manchete do jornal paulistano cria um título irônico, para o caso do músico, negro, assassinado pelo Exército em um carro em que a vítima estava junto com a sua família. Essa notícia, dias depois do crime, foi publicada como resposta acerca da violência, um posicionamento desumano que neutraliza o impacto emocional sofrido pela família, sustentado pela argumentação de uma "bobeada", ou seja, ausência de atenção, um descuido por parte do Exército.

É possível inferir que o assassinato de um ser humano por uma instituição de segurança pública é comum e acontece por uma falta de atenção, ainda mais alarmante é a acolhida da irresponsabilidade por parte do general. Oitenta tiros! Qual era a intenção do Exército se não o extermínio? É chocante, desconcertante e até repulsivo tentar refletir sobre 
tal posicionamento, pois está afastado de qualquer possibilidade empática, de qualquer direito civil, gerando novamente uma relativização da violência por parte das instituições que deveriam garantir a segurança, além da institucionalização da violência.

Para que o leitor alcance o entendimento do que se trata a notícia, o jornal publica "ação com 80 tiros no RJ" recuperando o crime para que o leitor seja relembrado das notícias publicadas anteriormente. Essa notícia traz dois dados novos: a quantidade de tiros e o posicionamento do general. É irônica, no sentido de opor o numeral 80 ao adjetivo "bobeada", como se fosse possível, por lapso, fuzilar um carro em movimento.

Buscando uma repercussão midiática, o jornal escolhe suas marcas enunciativas. Aqui também podemos perceber o silenciamento em relação aos seres humanos envolvidos. Como dito, só é possível estabelecer uma conexão do que se trata a notícia pela marca " 80 tiros no RJ", exaustivamente propagada em diversos jornais. É interessante observar ainda que acima do título está escrito: "segurança pública", obviamente uma alusão ao setor que essa notícia se encaixa dentro do jornal, porém promove também a associação com um efeito irônico, afinal, segurança de quem?

Proponho a seguinte reescrita da manchete: Comandante de ação, que matou homem negro e feriu sua família com 80 tiros no RJ, "deu uma bobeada”, diz general Heleno. Resolvi incluir entre vírgulas o responsável do ato criminoso, assim como expressar textualmente a condição social das vítimas, "negros", "morto" e "feridos", a fim de promover uma atribuição de sentido sobre quem matou, quem morreu, quem se feriu.

Por fim, segue a única manchete que não faz uso de algum tipo de retomada discursiva: 


\section{Designer de interiores é morto dentro de veículo de aplicativo durante abordagem policial}

Familiares disseram que ele voltava para casa quando foi atingido pelos disparos.

Por Anderson Barbosa, G1 SE - Aracaju

09/04/2019 06h36 : Atualizado há 4 dias

I) (2) 细 (

Fonte: G1 - TV Sergipe (2019)

A manchete do jornal sergipano contribui para que uma violência brutal seja relativizada pela sociedade. Silencia-se perante três fatos: a cor, o sexo e o motivo da morte. O título da notícia impede qualquer inferência a respeito desses fatores - determinantes para a completa atribuição da condição injusta que sofrera o assassinado. A cor: substituída pela profissão; o sexo: indeterminado, efeito da escolha que privilegia a profissão; o motivo da morte: apagado.

Apagar a adjetivação da característica física, da cor da pele da vítima, resulta no distanciamento da promoção de sentido atribuída à ideia de racismo por parte da "abordagem policial", derivando a relativização da violência e a impossibilidade de responsabilidade.

Noticiar os fatos e torná-los acessíveis à população é possibilitar o anúncio de um enunciado mais detalhado de descrições factuais e menos expostos a um posicionamento parcial, podendo gerar uma atribuição de sentido mais representativa da condição do objeto.

Podemos perceber, em uma análise ingênua, uma tentativa de $o$ jornal perseguir uma postura neutra, por meio de uma seleção lexical a evitar uma exposição da condição da vítima e possíveis problemas com a opinião pública. Contudo, vale refletir sobre as implicações contidas nessa manchete. "Designer de interiores" é uma adjetivação que classifica a vítima, deixando de focalizar o seu algoz. "É morto" por quem? Por quê? "Durante uma abordagem policial", uma situação inusitada. Expor uma perspectiva em relação ao agredido, ou seja, um olhar para quem sofre 
a agressão - vítima como foco, é sugerir uma banalização da violência, pois, ao defrontarmos com notícias várias de natureza violenta, passamos a acreditar que é comum ser morto e nos condicionamos a culpabilizar a vítima, vulgarizando enunciados do tipo: "Nossa, mas o que a pessoa estava fazendo?", "Não pode ser boa coisa", "Gente de bem não morreria assim”, "Se estivesse em casa, isso não aconteceria”.

Visto que a atribuição de sentido se dá entre a relação texto e leitor, o jornal impede que as condições enunciativas definidas na notícia atinjam um efeito questionador. Nesse processo, como já mencionado, é silenciada a possível atribuição de sentido sobre o preconceito racial, principal motivador do crime. Desse modo, o jornal, buscando uma pseudoneutralidade, uma falsa preocupação discursiva social equilibrada, não eleva o posicionamento da notícia como um crime baseado em injustiça e preconceitos, perpetuando esses estereótipos e aleijando a população de uma possível discussão e reflexão.

Proponho a reescrita da manchete nesses termos: Abordagem policial mata, dentro de veículo de aplicativo, designer de interiores negro. Procurei alterar o foco enunciativo reconstruindo a manchete a partir da ação do agente: "Abordagem policial mata" a fim de marcar o responsável pelo assassinato. Optei ainda por adicionar mais um adjetivo, "negro", após a caracterização da vítima no intuito de promover uma rápida atribuição de sentido sobre a possível motivação do crime.

\section{Considerações finais}

Ao escrever este trabalho em conjunto com a professora, deparei-me com muitas incertezas, reconheci em mim um estado de angústia e pensei algumas vezes que não seria possível continuar. Um trabalho dessa natureza mobiliza reflexão e empatia, conhecimentos linguísticos e extralinguísticos, além de um exercício constante de autorreconhecimento.

Por outro lado, a escrita só foi possível, pois foi auxiliada, orientada e construída em conjunto, e daí talvez tenha nascido um processo de autoria profícuo, porque compartilhado por mãos que, por seguirem juntas, respeitaram o compasso de uma e de outra, tocando afinadas sobre as 
teclas que revelavam suas inclinações e perspectivas discursivas, em signos ideológicos que buscavam o seu lugar no dizer. Escrever também foi uma oportunidade de refletir sobre a liberdade, os direitos e a possibilidade de diminuir injustiças. Além de reconhecer o meu lugar como acadêmico em uma Instituição de Ensino Superior, pública e de qualidade. Esse lugar tão atacado e desmerecido.

Nesse sentido, a nossa proposta de escrita se baseou no silêncio metafórico, na ausência de cor da negritude, que alicerçou a construção de sentido das manchetes jornalísticas. Em outras palavras, o silenciamento, o apagamento, a substituição, de determinadas nomeações constitutivas no texto contribuíram para a manutenção de um juízo coletivo, que priva o leitor de uma capacidade emancipatória e autônoma de atribuição de sentido, renegando-o às conformidades estabelecidas textualmente, provocando uma sensação de normalidade perante a exclusão social do indivíduo noticiado.

A impossibilidade de uma manchete imparcial e apolítica é evidente, assim como um posicionamento é inerente ao enunciado, mesmo que não esteja registrado na superfície textual, pois cada enunciado vai expressar seus componentes ideológicos e seu posicionamento norteador, em maior ou menor grau de exposição.

Diante disso, cabe ao leitor o discernimento das tendências enunciativas, a capacidade de fazer uma leitura crítica e eleger a sua fonte de informação. Mas para isso acontecer é preciso ensinar. Ensinar o exercício da leitura de diferentes fontes, no sentido de conceber as multiplicidades dos discursos imbricados nas pautas jornalísticas praticando a compreensão dos efeitos produzidos pelos comportamentos discursivos em cada uma delas. Para isso é preciso defender a educação gratuita e de qualidade para toda a sociedade brasileira, para que seja possível a formação de professores e outros agentes sociais transformadores.

O nosso trabalho tentou demonstrar que a imparcialidade da impressa é uma falácia, e a tentativa de perseguir essa tortuosa iniciativa resulta na exclusão de determinados grupos mantendo uma situação disforme da realidade. Nenhuma das manchetes jornalísticas menciona a cor da pele do cidadão assassinado, essa escolha poderia derivar de uma ilusão caracterizada como "imparcialidade", já discutida como controversa, visto que a atribuição de sentido se dá na relação entre o texto e o leitor. 
Portanto nos ocupamos por marcar o apagamento da caracterização física, no intuito de ampliar a possibilidade de sentidos ao leitor e de modificar o panorama discursivo instituído. Como observado, há nas manchetes um apagamento referente à cor da pele da vítima e esse apagamento, gerado pela falta de adjetivação específica, é substituído pela profissão. No caso, negro é substituído por: músico, segurança ou designer de interiores. Nesse processo "imparcial" de ressignificação se perde a possibilidade de construção de sentido por parte do leitor sobre o preconceito racial, principal motivador do crime.

Desse modo, os jornais, ao construir uma neutralidade e assumir uma preocupação discursiva social equilibrada, meramente ilusórias, não eleva o posicionamento da notícia como um crime baseado em injustiça e preconceitos, perpetuando, assim, uma adoção discursiva excludente.

Em síntese, podemos refletir, a partir da leitura do trabalho, como as manchetes dos jornais aqui apresentados podem colaborar para a manutenção das relações sociais vigentes, em que uma minoria não é representada nas páginas de jornais por uma série de injustiça sofridas, mas é essa mesma minoria invocada, adjetivada e explicitada, quando se trata de um crime por ela cometido.

\section{Referências}

BAKHTIN, M. (1942-1945). Questões de estilística no ensino da língua. Tradução de Sheila Grillo e Ekaterina Vólkova Américo. São Paulo: Editora 34, 2013.

BAKHTIN, M. (Volochínov, V.). (1929). Marxismo e filosofia da linguagem. Tradução de Michel Lahud e Yara Frateschi Vieira. 13. ed. São Paulo: Hucitec, 2009.

BAPTISTA, M. M. Estudos culturais: o quêe o como da investigação. Carnets, [s.l.], n. -1, p. 451-461, 1 jun. 2009. Open Edition. http://dx.doi. org/10.4000/carnets.4382. Disponível em: https://journals.openedition. org/carnets/4382. Acesso em: 19 maio 2020. 
BHAZ. 'O Exército não matou ninguém não': Bolsonaro classifica fuzilamento com 80 tiros como 'incidente'. 2019. Disponível em: <https:// bit.ly/2IvolvB > . Acesso em: 13 abr. 2019.

BRAZILIENSE, Correio. 'O Exército não matou ninguém, não', diz Bolsonaro sobre músico fuzilado: Presidente falou pela primeira vez desde que o caso ocorreu, em 7 de abril, e disse que o fato se tratou de um “incidente". 2019. Postado em 12/04/2019 14:50 / atualizado em 12/04/2019 15:32. Disponível em: <https://bit.ly/2GjKriU>. Acesso em: 13 abr. 2019.

CORREIO. 'O Exército não matou ninguém', diz Bolsonaro sobre morte de músico no Rio. 2019. UOL; MACHADO, 12.04.2019, 14:47:27 Atualizado: 12.04.2019, 14:57:31. Disponível em: <https://glo.bo/2KBNpn9>. Acesso em: 13 abr. 2019.

IBAHIA; GLOBO, Agência O. Bolsonaro sobre músico fuzilado: 'O Exército não matou ninguém'. 2019. Disponível em: <https://glo. bo/2DbJ97Z>. Acesso em: 13 abr. 2019.

MOITA-LOPES, L. P. (org.). Por uma Linguística Aplicada Indisciplinar. São Paulo: Parábola, 2006.

RIBEIRO, D. Podcast Matéria Bruta | Lugar de fala. 2019. 11m. Disponível em: https://youtu.be/SSaSfc4eJCQ. Acesso em: 19 maio 2020.

SE, G1. Designer de interiores é morto dentro de veículo de aplicativo durante abordagem policial: Familiares disseram que ele voltava para casa quando foi atingido pelos disparos. 2019. 09/04/2019 06h36 atualizado há 4 dias. Disponível em: <https://glo.bo/2IodmUr>. Acesso em: 13 abr. 2019.

SOBRAL, A. A concepção de autor do "Círculo de Bakhtin, Medvedev, Voloshinov: confrontos e definições. Macabéa - Revista Eletrônica do Netli, Crato, v. 1, n. 2, dez. 2012, p. 123-142.

UOL. Comandante de ação com 80 tiros no RJ “deu uma bobeada", diz general Heleno. 2019. Demétrio Vecchioli* e Luís Adorno Colaboração para o UOL e do UOL, em São Paulo 13/04/2019 14h16. Disponível em: $<$ https://bit.ly/2v5NeGm>. Acesso em: 13 abr. 2019. 
UOL; MACHADO, Priscila. Bahia apresenta o maior número de negros. 2013. Disponível em: <https://bit.ly/2JI7l2u $>$. Acesso em: 20 abr. 2019.

VISCARDI, J. MANCHETES IMPORTAM. 2020. 9m16s. Disponível em: https://www.youtube.com/watch?v=A6-g5YM9zRM. Acesso em: 19 maio 2020.

PLANALTO. Conheça as atribuições do presidente da República: chefe do executivo é o representante público mais elevado do país. 2019. Disponível em: http://www2.planalto.gov.br/mandatomicheltemer/acompanheplanalto/noticias/2018/12/conheca-as-atribuicoes-do-presidente-darepublica. Acesso em: 23 maio 2020. 